\title{
Life-threatening neurological complications after bone marrow transplantation in children
}

\author{
D Uckan ${ }^{1}$, M Cetin ${ }^{1}$, I Yigitkanli ${ }^{1}$, I Tezcan ${ }^{2}$, M Tuncer $^{1}$, D Karasimav ${ }^{1}$, KK Oguz ${ }^{3}$ and M Topçu ${ }^{4}$ \\ ${ }^{1}$ Department of Pediatrics, Units of Bone Marrow Transplantation and Hematology, Ankara, Turkey; ${ }^{2}$ Department of Pediatrics, \\ Units of Bone Marrow Transplantation and Immunology, Ankara, Turkey; ${ }^{3}$ Department of Radiology, Hacettepe University Faculty \\ of Medicine, Ankara, Turkey; and ${ }^{4}$ Department of Pediatrics, Units of Bone Marrow Transplantation and Neurology, Ankara, \\ Turkey
}

\section{Summary:}

Neurological complications may occur in BMT recipients (11-59\%), frequently contributing to morbidity or mortality. They are the main causes of death in 10-15\%. Lifethreatening neurological complications were seen in 11 out of $113(9.7 \%)$ children who underwent BMT from HLAmatched family $(n=7)$ or mismatched donors $(n=4)$ at our institution. Diagnoses of patients with neurological complications were acute myeloblastic leukemia (AML) (five), thalassemia major (two), Fanconi anemia (two), Omenn syndrome (one) and leukodystrophy (one), and the neurological events were seen between days +13 and +85 after transplantation. Minor symptoms including reversible, nonrepetitive seizures were excluded. Cyclosporine A toxicity was diagnosed in six children. The rest of the complications were brain abscess/meningoencephalitis (two), severe hypomagnesemia (one), busulfan toxicity (one), sustained hypertension (three), and intracranial hemorrhage (three). Six patients with neurological complications suffered from $>$ grade II graft-versus-host disease (GvHD), and all were high risk for transplantrelated complications. In this study, risk status of the underlying disease, mismatched transplantation, a diagnosis of AML (advanced stage), older age and > grade II GvHD were important adverse factors for the development of severe life-threatening neurological complications. Bone Marrow Transplantation (2005) 35, 71-76.

doi:10.1038/sj.bmt.1704749

Published online 8 November 2004

Keywords: neurological complication; children

Neurological complications have been described as an important cause of treatment-related morbidity and mortality in bone marrow transplantation (BMT) patients. ${ }^{1-7}$

Correspondence: Dr Duygu Uçkan, Hacettepe University Faculty of Medicine, Children's Hospital, Hematology/Bone Marrow Transplantation Unit, Yenisehir, Ankara 06100, Turkey;

E-mail: duckan@hacettepe.edu.tr

Received 5 December 2003; accepted 27 August 2004

Published online 8 November 2004
Although neurological complications have been described in $11-59 \%$ of BMT patients, ${ }^{1,2,5,6}$ neuropathological findings have been reported in more than $90 \%$ of autopsies studied. The most common autopsy findings have been reported as subarachnoid and intraparenchymal hemorrhage with a $58.7 \%$ incidence of cerebrovascular complications, fungal infection, Wernicke encephalopathy, microglial nodular encephalopathy and toxoplasmosis. ${ }^{7}$

The clinical presentation in the early post-transplant period has most frequently included convulsions, cranial palsies and symptoms consistent with increased intracranial pressure. ${ }^{1,3,6,8,9}$ Cyclosporine A (CsA) metabolic encephalopathy has been described as one of the most important etiological factors for development of neurological symptoms. ${ }^{4,8}$ Other causes leading to neurological complications have been reported to be systemic infection, cerebrovascular lesions, microangiopathy, busulfan-induced seizures, or other transplant-related factors. ${ }^{5,6}$

Previous studies have suggested unrelated or alternative donor allogeneic transplantation as the most important risk factor for development of neurological complications in children $^{1,2}$ and adults. ${ }^{3}$ Alternative donor transplants are associated with more profound immunosuppression and an increased treatment-related morbidity and mortality. ${ }^{1,3,5,6}$ Here, we retrospectively investigated the incidence and outcome of severe/life-threatening neurological complications in pediatric BMT patients allografted from an HLAmatched or mismatched donor.

\section{Patients and methods}

A total of 113 patients underwent allogeneic BMT at the Bone Marrow Transplantation Unit of Hacettepe University İhsan Doğramacı Children's Hospital. Patient ages ranged from 1.5 months to 18 years (mean age 4 years), with 71 males and 42 females. The underlying disease was either a malignant hematological condition $(n=39)$ or nonmalignant condition $(n=74)$. In all, 98 patients received bone marrow as the stem cell source, 12 mobilized peripheral blood $(\mathrm{PB})$ and three patients received cord blood (two unrelated). A total of 92 patients received stem cells from an HLA-identical family donor (one cord blood), 19 from an HLA-non-identical family donor and two unrelated cord blood cells (Table 1). 
Table $1 \quad$ Patient and transplant characteristics

\begin{tabular}{|c|c|c|c|}
\hline & Neurologic events $(-)(\mathrm{N}=102)$ & Neurologic events $(+)(\mathrm{N}=11)$ & $P$ \\
\hline Age: median (range) & 4 years (1.5 months -18 years) & 11 years ( $2-16$ years) & \\
\hline Sex: $M / F$ & $63 / 39$ & $8 / 3$ & \\
\hline Malignancy & $34(33.3 \%)$ & $5(45.4 \%)$ & \\
\hline ALL & $7(6.8 \%)$ & - & \\
\hline AML & $8(7.8 \%)$ & $5(45.4 \%)$ & 0.001 \\
\hline CML & $7(6.8 \%)$ & - & \\
\hline MDS & $10(9.8 \%)$ & - & \\
\hline NHL & $1(0.9 \%)$ & - & \\
\hline Neuroblastoma & $1(0.9 \%)$ & - & \\
\hline Nonmalignancy & $68(66.6 \%)$ & $6(54.5 \%)$ & \\
\hline AA & $4(3.9 \%)$ & - & \\
\hline Thalasemia & $8(7.8 \%)$ & $2(18 \%)$ & \\
\hline FAA & $5(4.9 \%)$ & $2(18 \%)$ & \\
\hline Osteopetrosis & $5(4.9 \%)$ & - & \\
\hline SCID & $28(27.8 \%)$ & - & \\
\hline Other immunological diseases & $10(9.8 \%)$ & $1(9 \%)$ & \\
\hline Metabolic diseases & $8(7.8 \%)$ & $1(9 \%)$ & \\
\hline \multicolumn{4}{|l|}{ Conditioning regimen } \\
\hline Radiation & $8(7.8 \%)$ & - & \\
\hline Busulfan & $67(65.6 \%)$ & $10(90.9 \%)$ & \\
\hline Other & $4(3.9 \%)$ & $1(9 \%)$ & \\
\hline No conditioning & $23(22.5 \%)$ & - & \\
\hline \multicolumn{4}{|l|}{ Source of stem cells } \\
\hline $\mathrm{BM}$ & $93(91.1 \%)$ & $5(45.4 \%)$ & $<0.01$ \\
\hline PBSC & $7(6.8 \%)$ & $5(45.4 \%)$ & $<0.01$ \\
\hline Umbilical cord blood & $2(1.9 \%)$ & $1(9 \%)$ & \\
\hline Matched family & $86(84.3 \%)$ & $6(54.5 \%)$ & \\
\hline Mismatched family & $15(14.7 \%)$ & $4(36.3 \%)$ & $<0.05$ \\
\hline Unrelated cord blood & $1(0.9 \%)$ & $1(9 \%)$ & \\
\hline GvHD > grade II & $10(9.8 \%)$ & $4(36.3 \%)$ & $<0.05$ \\
\hline Standard risk & $52(50.9 \%)$ & - & $<0.01$ \\
\hline High risk & $50(49 \%)$ & $11(100 \%)$ & $<0.01$ \\
\hline Very high risk & $11(10.7 \%)$ & $8(72.7 \%)$ & $<0.01$ \\
\hline
\end{tabular}

$\mathrm{ALL}=$ acute lymphoblastic leukemia, $\mathrm{AML}=$ acute myelogenous leukemia; $\mathrm{CML}=$ chronic myelogenous leukemia; $\mathrm{MDS}=$ myelodysplastic syndrome; $\mathrm{NHL}=$ non-Hodgkin's lymphoma; AA = aplastic anemia; FAA = Fanconi aplastic anemia; SCID = severe combined immunodeficiency; $\mathrm{BM}=$ bone marrow; $\mathrm{PBSC}=$ peripheral blood stem cell; $\mathrm{GvHD}=$ graft-versus-host disease.

Patients were categorized as standard, high risk or very high risk for transplant-related morbidity/mortality according to the risk status of the underlying disease, degree of HLA typing, comorbidity factors of the patient including prior treatment history. All patients with an advanced stage of leukemia $\geqslant 2$ nd complete remission (excluding cases with standard indications for BMT, such as standard risk ALL transplanted in CR2 or AML M3 in CR2) or nonremission for acute leukemia; > first chronic phase for chronic myelocytic leukemia; multiple $(>20)$ and inappropriate (without the use of leukocyte filters or from related donors) transfusion history for aplastic anemia; Class III thalassemic patients; and semi-synthetic androgen (oxymethalone) use, multiple transfusion history and the presence of multiple anomalies for Fanconi aplastic anemia; and very advanced stage of the underlying disease were considered as diseaserelated risk factors for transplantation. The presence of $\geqslant 2$ high-risk factors was considered as very high risk for transplant-related morbidity/mortality.
Only severe (life-threatening) neurological complications were included in this study. Benign and self-limiting conditions such as nonsevere headache, tremor, mild extrapyramidal symptoms, myopathy, hiccups and simple, reversible, nonrepetitive seizures of short duration $(<3 \mathrm{~min})$ not associated with significant follow-up EEG findings were excluded. A life-threatening neurological event was defined as a neurological event that contributed to death or significant worsening of the clinical condition of the patient, or, alternatively, when a neurological event developed in a critically sick patient and contributed to death. Patients with encephalopathy and persistent changes in consciousness, clinical findings suggesting brain edema, cranial nerve involvement, hemiparesis and those with repetitive or prolonged seizures were included. The patients with neurological events were defined as neuro $(+)$ and those without neurological complications as neuro(-).

Busulfan-based conditioning regimens were used in most of the patients (Table 1). Melphalan was added in cases 
with AML transplanted recently. ATG was used in multiply transfused patients or in those with alternative donors. Patients with Fanconi anemia received low-dose thoracoabdominal irradiation and cyclophosphamide; however, recently, nonradiation regimens consisting of low-dose busulfan and cyclophosphamide were used. $\mathrm{CsA}+/-$ methotrexate (MTX) +/-steroids or ATG was given as graft-versus-host disease (GvHD) prophylaxis. Antibacterial, antifungal, antiviral prophylaxis was administered until day +30 , and intravenous immunoglobulin until day +180 . Granulocyte-colony-stimulating factor (G-CSF) was given from day +7 until engraftment. Acute GvHD was diagnosed and graded according to Seattle criteria. ${ }^{10}$ Steroids, CsA, tacrolimus, mycophenolate mofetil, daclizumab, or inflixumab were used for treatment of GvHD. Hepatic veno-occlusive disease was diagnosed according to Seattle criteria. ${ }^{11}$

\section{Statistical analysis}

Statistical comparisons were completed using the $\chi^{2}$ test for independence, or Fisher's exact probability test. Survival rates were calculated using the Kaplan-Meier method.

\section{Results}

\section{Neurological complications}

Neurological complications were seen in 11 out of 113 $(9.7 \%)$ patients (Table 1). Patient and transplant characteristics of neuro $(+)$ patients are listed in detail in Table 2. All of those complications were seen within the first 3 months after transplantation (range day -4 to +85 ). Table $3 \mathrm{a}$ and $\mathrm{b}$ summarizes neurological events, laboratory and imaging findings of neuro $(+)$ patients. Seven children suffered one or more seizure episodes. Stroke $(n=1)$, very severe headache $(n=1)$, or cranial nerve palsies $(n=4)$ were other clinical presentations. Cerebrovascular events were diagnosed in three patients, two patients had intracranial infection and six patients suffered from drug toxicity (CsA, busulfan) and metabolic causes. The neurological symp- toms of case 3 who had severe pre-transplant cardiomyopathy were initially attributed to a thromboembolic event or CsA toxicity, but the patient received multiple antibiotics, since infection could not be ruled out, and developed systemic toxicity (Figures 1 and 2). He underwent extensive diagnostic/therapeutic procedures including brain biopsy, which failed to show an infectious etiology and was diagnosed as suffering from CsA toxicity after autopsy. In eight patients neurological events were seen when the patients were already suffering from severe clinical conditions and had major organ dysfunction in at least two systems, including multiorgan failure in five. In three patients neurological symptoms developed before the patient's clinical condition worsened and the particular event contributed to death (cases 5,10 ) or sequela (case 4).

Out of 102 patients, 33 who did not suffer from a severe acute neurological symptom died, whereas 10 of 11 neuro $(+)$ patients died. Overall survival for the whole group was $52.7 \pm 7.6 \%$ at 6 years. Survival in the neuro $(+)$ group was $9 \pm 8 \%$, whereas it was $65 \pm 5 \%$ in the neuro $(-)$ group $(P<0.001)$.

\section{Pre-transplant risk factors}

All neuro $(+)$ patients had high-risk factors pre-transplant for BMT-related morbidity and mortality, whereas 50 out of $102(49 \%)$ neuro( -$)$ patients were considered as highrisk patients (Table 1$)(P<0.01)$. When high-risk patients were further divided, eight of $11(72.7 \%)$ neuro $(+)$ patients were very high-risk patients and 11/102 (10.7\%) neuro(-) patients had very high-risk factors $(P<0.01)$.

Patient characteristics of neuro $(+)$ and neuro $(-)$ groups are shown in Table 1. The mean age of neuro $(+)$ and neuro(-) patients (excluding severe combined immunodeficiency (SCID) patients who did not receive conditioning) was, respectively $10.2 \pm 3.9$ and $5.8 \pm 4.5$ years $(P<0.001)$. Severe neurological symptoms were seen more frequently in patients with GvHD over grade II $(P<0.05)$, in mismatched transplant recipients $(P<0.05)$, in patients with a diagnosis of AML $(P=0.001)$ and when peripheral blood was used as stem cell source $(P<0.01)$.

Table 2 Patient and transplant characteristics of neuro $(+)$ patients

\begin{tabular}{|c|c|c|c|c|c|c|c|}
\hline Pt no. & $\begin{array}{c}\text { Age } \\
(\text { years }) / \operatorname{sex}\end{array}$ & $\begin{array}{l}\text { Primary } \\
\text { disease }\end{array}$ & $\begin{array}{l}\text { Pretransplant } \\
\text { neurological status }\end{array}$ & $\begin{array}{l}\text { Transplant } \\
\text { type }\end{array}$ & $\begin{array}{l}\text { Preparative } \\
\text { regimen }\end{array}$ & $\begin{array}{l}\text { GvHD } \\
\text { prophylaxis }\end{array}$ & Engraftment \\
\hline 1 & $16 / \mathrm{F}$ & AML(relapse) & Normal & HLA 6/6 sibling BM & $\mathrm{BuCy} / \mathrm{AraC}$ & $\mathrm{CsA} / \mathrm{MTX}$ & + \\
\hline 2 & $7 / F$ & GLD(advanced) & Vegetative state & HLA 5/6 unrelated cord & $\mathrm{BuCy} / \mathrm{ATG}$ & CsA/MTX & + \\
\hline 3 & $11 / \mathrm{M}$ & $\mathrm{AML}(\mathrm{CR} 2)$ & Normal & HLA 5/6 father PBSC & $\mathrm{Bu} / \mathrm{Mel} / \mathrm{ATG}$ & $\mathrm{CsA}$ & + \\
\hline 4 & $5 / \mathrm{M}$ & T.Major(class III) & Normal & HLA 6/6 sibling BM & $\mathrm{BuCy}$ & CsA/MTX & + \\
\hline 5 & $5.5 / \mathrm{M}$ & AML(relapse) & Normal & HLA $6 / 6$ sibling BM & $\mathrm{BuCy} / \mathrm{Mel}$ & $\mathrm{CsA}$ & + \\
\hline 6 & $8 / \mathrm{M}$ & AML nonremission (+ SCID) & Normal & HLA $6 / 6$ father PBSC & $\mathrm{BuCy}$ & CsA/MTX & + \\
\hline 7 & $16 / \mathrm{M}$ & AML(relapse) & Normal & HLA 4/6 father BM & $\mathrm{BuCy} / \mathrm{Mel} / \mathrm{ATG}$ & $\mathrm{CsA} / \mathrm{MTX} / \mathrm{MPZ}$ & + \\
\hline 8 & $11 / \mathrm{M}$ & T.Major(class III) & Normal & HLA $6 / 6$ sibling BM/PBSC & $\mathrm{Flu} / \mathrm{BuCy}$ & $\mathrm{CsA} / \mathrm{MTX}$ & + \\
\hline 9 & $13 / \mathrm{M}$ & FAA(aplastic) & Normal & HLA 6/6 sibling BM & $\mathrm{Bu}^{\mathrm{a}} \mathrm{Cy} 20$ & CsA/MTX & + \\
\hline 10 & $2 / \mathrm{F}$ & Omenn syndrome & Normal & HLA 5/6 mother PBSC & Flu/ATG & CsA & + \\
\hline 11 & $13 / \mathrm{M}$ & FAA(aplastic) & Normal & HLA 6/6 sibling PSBC & $\mathrm{Bu}^{\mathrm{a}} / \mathrm{Cy} 20$ & CsA & + \\
\hline
\end{tabular}

${ }^{\mathrm{a}}$ Low dose.

$\mathrm{BU}=$ busulphan; AraC = cytarabine; $\mathrm{CY}=$ cyclophosphamide; $\mathrm{MTX}=$ methotrexate; $\mathrm{Flu}=$ fludarabin; $\mathrm{CsA}=\mathrm{cyclosporine} \mathrm{A} ; \quad \mathrm{Mel}=\mathrm{melphalan}$; $\mathrm{FAA}=$ Fanconi aplastic anemia; AML = acute myelogenous leukemia; GLD = globoid cell leukodystrophy; ATG = antithymocyte globulin; SCID = severe combined immune deficiency; $\mathrm{MPZ}=$ methyl prednisolone; $\mathrm{CR}=$ complete remission. 
(a) Complications and outcome of neuro(+) patients; (b) Summary of neuro-imaging and laboratory studies of neuro( + ) patients

\begin{tabular}{|c|c|c|c|}
\hline \multicolumn{4}{|l|}{ (a) } \\
\hline Pt. & Non-neurological complications/severe & Neurological complication(onset) & Outcome \\
\hline 1 & $\begin{array}{l}\text { Left jugular venous thrombosis, Grade III } \\
\text { mucositis, massive GIT bleeding, SIADH }\end{array}$ & $\begin{array}{l}\text { Generalized tonic-clonic seizure (day }+42) \text {, left } \\
\text { hemiparesis, dysphagia, blurred vision }(\text { day }+36)\end{array}$ & Died at day +47 \\
\hline 2 & $\begin{array}{l}\text { Grade IV GvHD, massive epistaxis requiring } \\
\text { short-term intubation }\end{array}$ & $\begin{array}{l}\text { Generalized tonic-clonic seizure, repetitive (day } \\
+17 \text { ) }\end{array}$ & MOF, died at day +39 \\
\hline 3 & Severe cardiomyopathy & $\begin{array}{l}\text { Papiledema, loss of consciousness, seizure (day } \\
+28)\end{array}$ & $\begin{array}{l}\text { Varicella pneumonia, died at day } \\
+129\end{array}$ \\
\hline 4 & - & $\begin{array}{l}\text { Athetoic movements in the upper extremities (day- } \\
4 \text { ), left peripheal facial palsy }(\text { day }+13)\end{array}$ & Alive with sequela \\
\hline 5 & Hypertension & $\begin{array}{l}\text { Generalized tonic-clonic seizure, left facial palsy, } \\
\text { loss of conscious }(\text { day }+14)\end{array}$ & Respiratory failure, died at day +32 \\
\hline 6 & Grade IV GvHD & Loss of conscious, cranial nerve palsies $($ day +30$)$ & Respiratory failure, died at day +36 \\
\hline 7 & $\begin{array}{l}\text { Grade IV GvHD, severe epistaxis, grade III } \\
\text { mucositis }\end{array}$ & Focal seizure $($ day +60$)$ & MOF, died at day +77 \\
\hline 8 & $\begin{array}{l}\text { Grade III mucositis, moderate-severe VOD, } \\
\text { hypertension, pleural effusion }\end{array}$ & Very severe headache $($ day +30$)$ & $\begin{array}{l}\text { Graft rejection, pulmonary } \\
\text { haemorrhage, died at day }+38\end{array}$ \\
\hline 9 & Grade IV GvHD, CMV infection & Focal seizure $($ day +47$)$ & MOF, died at day +104 \\
\hline 10 & Grade III GvHD, catheter infection & Unilateral abducens palsy $($ day +85$)$ & MOF, died at day + 91 \\
\hline 11 & $\begin{array}{l}\text { Grade III-IV GvHD, insulin-resistant } \\
\text { hyperglycemia, hypertension }\end{array}$ & $\begin{array}{l}\text { Generalized tonic-clonic seizure (day }+26) \text {, } \\
\text { changes in consciousness }\end{array}$ & $\mathrm{MOF}$, died at day +46 \\
\hline \multicolumn{4}{|l|}{ (b) } \\
\hline Pt. & Neuro-imaging/EEG findings & Lab. findings & Presumed etiology \\
\hline 1 & $\begin{array}{l}\text { CT: normal } \\
\text { MRI: Pontine myelinolysis }\end{array}$ & $\mathrm{Na} 125 \mathrm{mEq} / \mathrm{lt}, \mathrm{CsA} 256 \mathrm{ng} / \mathrm{ml}, \mathrm{Mg} 1.3 \mathrm{mg} / \mathrm{dl}$ & CsA toxicity \\
\hline 2 & $\begin{array}{l}\text { MRI: Left cerebral subdural hematoma, Krabbe } \\
\text { disease } \\
\text { CT: Diffuse atrophy } \\
\text { EEG: Generalized encephalopathy }\end{array}$ & $\mathrm{Na} 128 \mathrm{mEq} / \mathrm{lt}$, CsA $517 \mathrm{ng} / \mathrm{ml}$ & CsA toxicity, subdural hematoma \\
\hline 3 & $\begin{array}{l}\text { MRI: Solitary lesions } \\
\text { CT: Right parietal acute infarct, diffuse atrophy }\end{array}$ & CsA $150 \mathrm{ng} / \mathrm{ml}, \mathrm{Mg} 1.8 \mathrm{mg} / \mathrm{dl}$ & CsA toxicity, acute infarct \\
\hline 4 & $\begin{array}{l}\text { CT: Epidural abcess osteomyelitis in occipital bone } \\
\text { MRI: Mastoiditis }\end{array}$ & CSF protein $300 \mathrm{mg} / \mathrm{dl}, 33$ cells $/ \mathrm{mm}^{3}$ & $\begin{array}{l}\text { Busulfan tocixity, intracranial } \\
\text { abcess, facial palsy }\end{array}$ \\
\hline 5 & EEG: Normal & CsA $1769 \mathrm{ng} / \mathrm{ml}, \mathrm{Mg} 0.8 \mathrm{mg} / \mathrm{dl}$ & CsA toxicity, hypomagnesemia \\
\hline 6 & CT: Hemorrhage & CsA $155 \mathrm{ng} / \mathrm{ml}, \mathrm{Mg} 0.7 \mathrm{mg} / \mathrm{dl}$ & Intracranial hemorrhage \\
\hline 7 & $\begin{array}{l}\text { CT: Frontal parietal hypodense area } \\
\text { EEG: Diffuse cerebral dysfunction }\end{array}$ & $\mathrm{Mg} 0.19 \mathrm{mg} / \mathrm{dl}$ & Hypomagnesemia \\
\hline 8 & $\begin{array}{l}\text { MRI: Bilateral frontal, right parietal, left occipital } \\
\text { subdural hematoma } \\
\text { EEG: Normal }\end{array}$ & $\mathrm{CsA} 250 \mathrm{ng} / \mathrm{ml}$ & Intracranial haemorrhage \\
\hline 9 & $\begin{array}{l}\text { CT: Normal } \\
\text { EEG: Paroxysmal activity at left hemisphere }\end{array}$ & CsA $184 \mathrm{ng} / \mathrm{ml}$ & CsA toxicity \\
\hline 10 & MRI: Meningoencephalitis & $\mathrm{CsA} 86 \mathrm{ng} / \mathrm{ml}$ & $\begin{array}{l}\text { Meningoencephalitis pseudotumor } \\
\text { cerebri }\end{array}$ \\
\hline 11 & $\begin{array}{l}\text { CT: Ventricular dilatation } \\
\text { EEG: Normal } \\
\text { CT: Hypodense areas } \\
\text { EEG: Diffuse suppression }\end{array}$ & CsA $279 \mathrm{ng} / \mathrm{ml}$ & CsA toxicity \\
\hline
\end{tabular}

GvHD = graft-versus-host disease; SIADH = syndrome of inappropriate secretion of antidiuretic hormone; CsA = cyclosporin $\mathrm{A} ; \mathrm{MOF}=$ multi-organ failure; $\mathrm{CMV}=$ cytomegalovirus; GIT = gastrointestinal tract; $\mathrm{VOD}=$ veno-occlusive disease.

\section{Discussion}

The reported incidence of neurological complications varies greatly among different centers, ranging from 11 to $59 \%{ }^{1,2,5,6}$ In patients with sickle cell disease with a previous history of stroke, neurological complications have been reported to occur in $50 \%$ of the patients during the transplant period. ${ }^{12}$ In addition, $90 \%$ of autopsies performed in BMT patients have revealed neuropathological findings. ${ }^{7}$ In the present study, benign conditions were excluded and life-threatening neurological complications were detected in $9.7 \%$ of pediatric BMT patients. However, our patient population consisting of SCID and other immunological/metabolic disorders is somewhat different from the average pediatric BMT unit where hematological diseases predominate.

All patients who experienced a severe neurological event were high-risk patients for transplant complications (eight very high risk, three high risk). None of the patients who did not receive conditioning ( $n=23$ SCID patients) and 

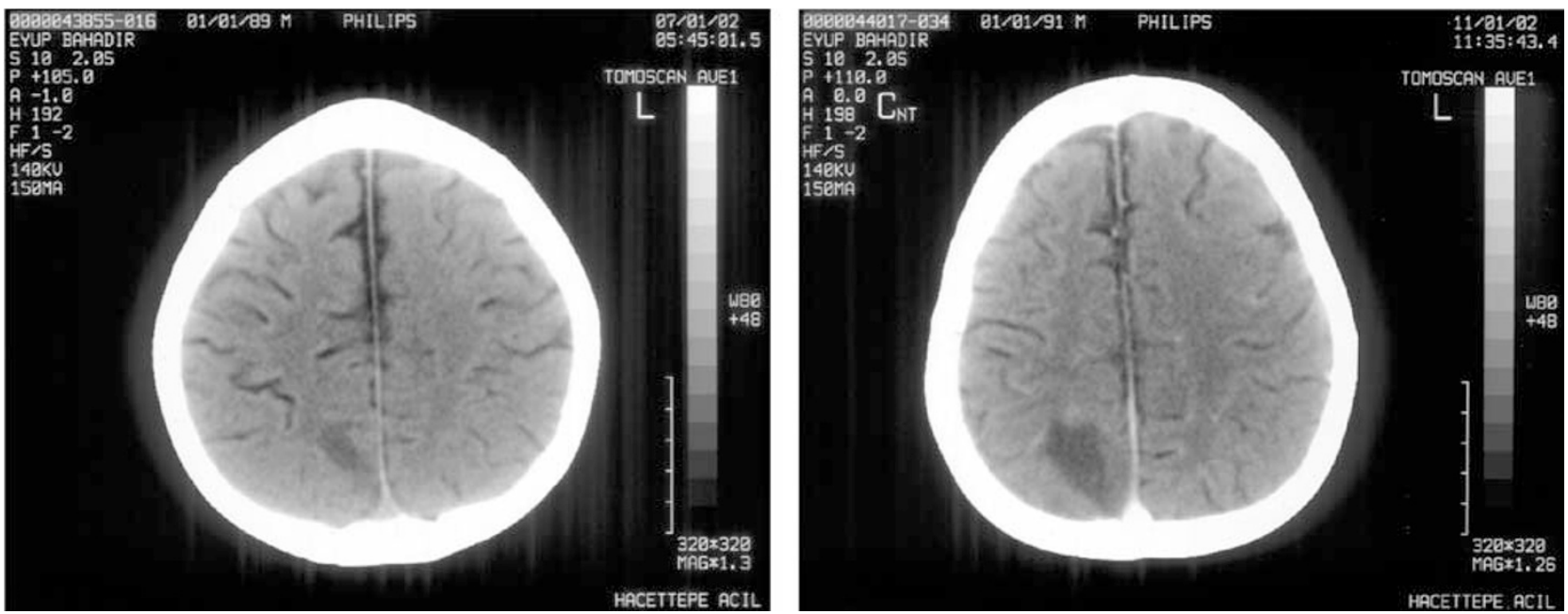

Figure 1 A focal hypodense lesion involving the cortex and subcortical white matter and narrowing of the neighboring sulci in the right parietal lobe was seen on the first CT imaging and with contrast 4 days later.
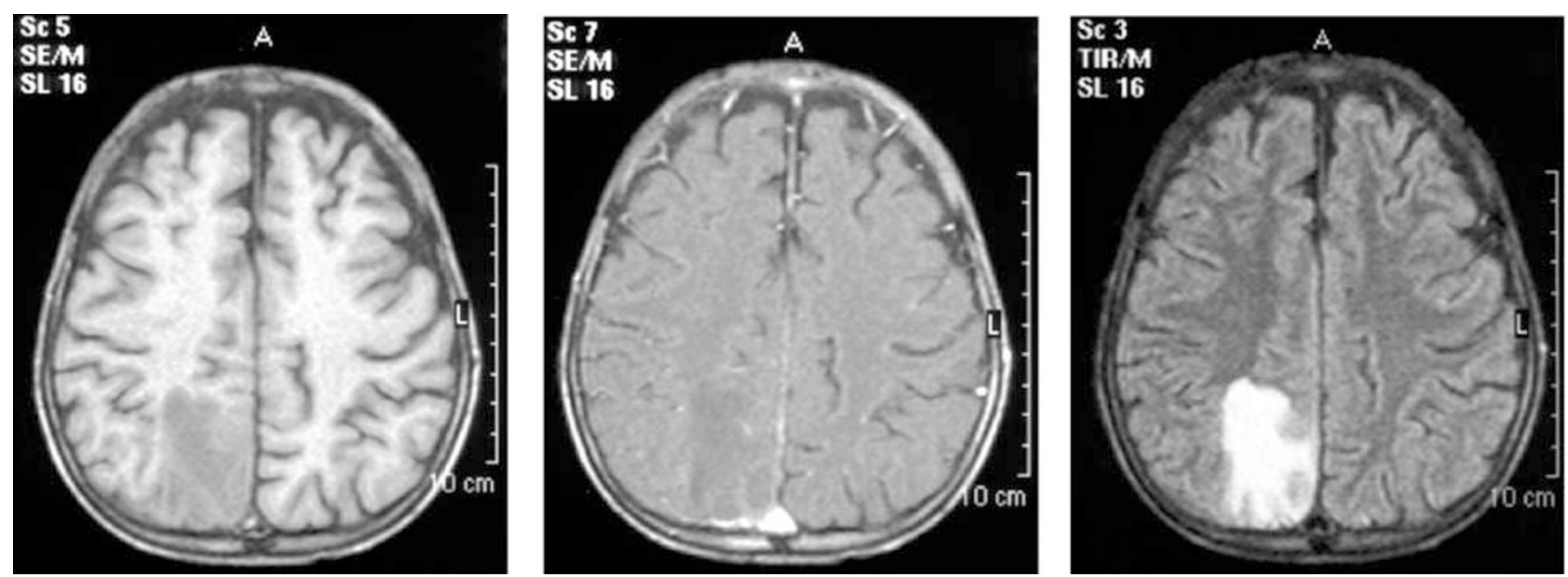

Figure 2 T1-weighted SE (TR/TE; 550/15) axial image obtained 4 days later ( 8 days after the first CT) showed that the lesion was hypointense, located peripherally involving the cortex and subcortical area and expanding with effacement of the sulci; contrast-enhanced T1W SE (TR/TE; 550/15) image showed that the lesion did not enhance and axial FLAIR (TR/TE/TI; 5000/100/1900) image displayed hyperintense lesion, respectively.

none of those in the standard risk group experienced a severe neurological event.

Eight of 11 patients developed a neurological complication when critically ill with a non-neurological condition, and the neurological event probably contributed to death. Thus, it may be stated that most patients experience neurological events before death when critically ill with non-neurological conditions, supporting the autopsy data reported by Bleggi-Torres et al. ${ }^{7}$ Seriously sick patients who are on multiple medications may suffer from drug interactions that may contribute to the neurological event. In the remaining three patients in this study, neurological events were followed by worsening of the patient's clinical status. Either discontinuation or lowering of CsA doses, initiation of new medications for management of the neurological findings, or hypoxia or organ dysfunction might have played a role in the development of further transplant complications such as GvHD, toxicity or graft failure.

Previous studies have shown that neurological symptoms are seen more frequently in the allogeneic and particularly unrelated transplant setting, indicating the presence of high-risk factors for transplant-related morbidity/mortality. ${ }^{1,3,5}$ In this study, neurological complications were seen more frequently in mismatched transplant recipients and in those with > grade II GvHD. Corticosteroids used during treatment of GvHD are known to influence CsA levels ${ }^{4-6}$ and may thus contribute to the development of neurological events. Seizures have been described in organ transplant recipients during rejection episodes and steroid use, and have been attributed to the focal breakdown of the blood-brain barrier. ${ }^{13}$ The use of other drugs and 
metabolic problems that arise in patients with GvHD may also be contributory factors. Among several medications used in transplant patients, CsA is a major one known to cause neurotoxicity. ${ }^{4-6,8}$ In the present study, CsA toxicity was defined according to the clinical, electrophysiological and imaging findings (most often involving the occipital lobe), regardless of CsA levels. Six of 11 neuro $(+)$ patients in this study suffered from CsA toxicity. These patients experienced cortical blindness, generalized convulsions, visual abnormalities and motor signs. EEG abnormalities included epileptiform discharges or focal slowing. MRI findings were supportive of the diagnosis, with leukoencephalopathy involving the occipital lobe. CsA-induced posterior leukoencephalopathy syndrome is generally described as a reversible condition; however, irreversible cases have also been reported. ${ }^{14}$ Toxicity is more frequently correlated with the rate of change of blood pressure. In cases 5, 8 and 11, hypertension might have contributed to the development of neurological symptoms associated with CsA toxicity or intracranial hemorrhage. CsA toxicity/ metabolic encephalopathy, cerebrovascular events and infection were the main causes of neurotoxicity in the high-risk pediatric BMT patients in this study.

Transplant patients are often receiving other medications and suffering from complicated clinical conditions that may cause a delay in diagnosis and treatment. In case 3 , with severe pre-transplant cardiomyopathy, the neurological complication was initially attributed to a thromboembolic event and/or CsA toxicity. As an infectious condition could not be ruled out (Figures 1 and 2), the patient underwent extensive diagnostic/therapeutic interventions, including brain biopsy, which failed to show an infectious etiology.

In this study, the mean age of the neuro $(-)$ patients appeared to be younger, which was attributed to the presence of SCID patients in this group. However, when SCID patients were excluded, older age at transplant was still a significant risk factor for neurological complications $(P<0.001)$.

In addition, peripheral blood stem cell use was more frequent among patients with neurological events, but since the number of peripheral blood stem cell transplants is small in this study it is not possible to draw conclusions.

When pre-transplant risk factors were further analyzed, a diagnosis of AML was a significant risk factor for the development of life-threatening neurological events in this study. Three of five patients with AML were not in remission at the time of transplant, two had advanced disease with a history of intensive treatment history and three patients possessed very-high-risk factors, suggesting that disease-related risk factors are as important for the development of neurological events.

In summary, the presence of $>$ grade II GvHD, mismatched transplantation, a diagnosis of AML (ad- vanced), older age and, most importantly, the patient's high-risk status for development of transplant complications were significant risk factors for development of severe neurological complications in pediatric BMT patients.

\section{References}

1 Iguchi A, Kobayashi R, Yoshida M et al. Neurological complications after stem cell transplantation in childhood. Bone Marrow Transplant 1999; 24: 647-652.

2 Wiznitzer M, Packer RJ, August CS, Burkey ED. Neurological complications of bone marrow transplantation in childhood. Ann Neurol 1984; 16: 569-576.

3 de Brabander C, Cornelissen J, Smitt PA et al. Increased incidence of neurological complications in patients receiving an allogenic bone marrow transplantation from alternative donors. J Neurol Neurosurg Psychiatry 2000; 68: 36-40.

4 Gleeson JG, DuPlessis AJ, Barnes PD, Riviello JJ. Cyclosporin A acute encephalopathy and seizure syndrome in childhood: clinical features and risk of seizure recurrence. J Child Neurol 1998; 13: 336-344.

5 Garrick R. Neurological complications. In: Atkinson K (ed). Clinical Bone Marrow and Blood Stem Cell Transplantation, 2nd edn. Cambridge University Press: Cambridge, UK, 2000, pp 958-979.

6 Oppenshaw H, Slatkin N. Neurological complications. In: Forman SJ, Blume KG, Thomas (eds). Bone Marrow Transplantation. Blackwell Scientific Publications: Oxford, UK, 1999, pp 659-673.

7 Bleggi-Torres LF, de Medeiros BC, Werner B et al. Neuropathological findings after bone marrow transplantation: an autopsy study of 180 cases. Bone Marrow Transplant 2000; 25: 301-307.

8 Trullemans F, Grignard F, Van Camp B, Schots R. Clinical findings and magnetic resonance imaging in severe cyclosporine-related neurotoxicity after allogeneic bone marrow transplantation. Eur J Haemotol 2001; 67: 94-99.

9 Coplin WM, Cochran MS, Levine SR, Crawford SW. Stroke after bone marrow transplantation; frequency, aetiology and outcome. Brain 2001; 124: 1043-1051.

10 Glucksberg H, Storb R, Fefer A et al. Clinical manifestations of graft-versus-host disease in human recipients of marrow from HL-A-matched sibling donors. Transplantation 1974; 18: 295-304.

11 McDonald GB, Sharma P, Matthews DE et al. Venocclusive disease of the liver after bone marrow transplantation: diagnosis, incidence, and predisposing factors. Hepatology 1984; 4: 116-122.

12 Walters MC, Sullivan KM, Bernaudin F et al. Neurologic complications after allogeneic marrow transplantation for sickle cell anemia. Blood 1995; 85: 879-884.

13 Vaughn BV, Ali II, Olivier KN et al. Seizures in lung transplant recipients. Epilepsia 1996; 37: 1175-1179.

14 Antunes NL, Small TN, George D et al. Posterior leukoencephalopathy syndrome may not be reversible. Pediatr Neurol 1999; 20: 241-243. 